\title{
A prospective study of morbidity patterns in ectopic pregnancy at a tertiary care hospital
}

\author{
Anis F ${ }^{1}$, Malarvizhi G ${ }^{2}$, Narmadha NS ${ }^{3}$, Reddy AS ${ }^{4}$ \\ ${ }^{1}$ Dr Fatima Anis, Junior Resident, ${ }^{2}$ Dr Malarvizhi G, Junior Resident, ${ }^{3}$ Dr Narmadha NS, Senior Resident, ${ }^{4}$ Dr Alla \\ Satyanarayana Reddy, Professor and HOD, all authors are attached with Department of Obstetrics and Gynaecology, \\ Vinayaka Mission's Medical College \& Hospital, Karaikal, Puducherry, India
}

Address for Correspondence: Dr Alla Satyanarayana Reddy, Professor, Department of Obstetrics and Gynaecology, Vinayaka Mission's Medical College, Karaikal, Puducherry, India

\begin{abstract}
Introduction: Ectopic pregnancy is potentially life-threatening and remains the leading cause of maternal death. The incidence of ectopic pregnancy is increased during last few years all over the world. Objective: To study the mortality and morbidity of Ectopic Pregnancy at a Tertiary Care Hospital. Methods: This prospective study conducted in the Department of Obstetrics \& Gynaecology of Vinayaka Mission's Medical College, Karaikal, Puducherry for a period of 2 years. 70 cases of ectopic pregnancy were diagnosed and recruited for the study. TVS / TAS was done to diagnose and also to ascertain the severity of the condition. Apart from routine surgical profile, $\beta$-hCG assay was also performed. Results: Out of 70 patients, $62(88.5 \%)$ patients were managed by laparotomy, $7(10 \%)$ patients were by laparoscopically, one patient (1.4\%) was successfully managed by medical therapy. The most common site for ectopic was found in ampulla in 52(74\%) patients, followed by isthmus $6(8.24 \%)$, ovary $5(7.14 \%)$, interstitial $1(1.4 \%)$, cornua $2(2.28 \%)$, fimbria $2(2.28 \%)$ and infundibulam 2(2.28\%). In our study group about morbidity, 67 cases post operative period was uneventful, 3 (4.2\%) cases were admitted in ICU. Conclusion: Early diagnosis of ectopic pregnancy and timely conservative surgical or medical management is essential to reduce the maternal morbidity and mortality and also helps in conserving fertility.
\end{abstract}

Key words: Ectopic pregnancy, Maternal morbidity and mortality

\section{Introduction}

Ectopic pregnancy is life threatening condition, and catastrophic \& one of the commonest acute abdominal emergency in day-to-day practice. It has been recognized for over 400 years and continues to be an increasing affliction affecting approximately $2 \%$ of all pregnancies. It remains as an important contributor to maternal morbidity and mortality \& one of the commonest causes of first trimester maternal death [1].

Women affected with ectopic pregnancy are not only exposed to complications from the ectopic pregnancy and the related treatment procedures, but are also at a greater risk of another ectopic pregnancy, and future reproductive challenges can be distressing.

Over subsequent years, the advent of new diagnostic techniques, blood transfusions aseptic precautions, antibiotics, anaesthesia combined to save the lives of

Manuscript received: $06^{\text {th }}$ September 2016

Reviewed: $15^{\text {th }}$ September 2016

Author Corrected: $20^{\text {th }}$ September 2016

Accepted for Publication: $30^{\text {th }}$ September 2016

Obsgyne Review: Journal of Obstetrics and Gynecology many women. Still late diagnosis and interventions are common. Now with recent advances the attention is shifted from saving lives to preserving fertility. Many improvements were done to diagnose and treat ectopic pregnancies, to limit its impact on women's health. The concept of "discriminatory cutoff" of $\beta$-hCG was developed in 1985 for the diagnosis and management of suspected ectopic pregnancies by medical and conservative surgical procedures to make the women eligible for future fertility [2]. It is defined as, the level of $\beta$-hCG at which a normal intrauterine pregnancy can be visualized by ultrasonography with sensitivity of $100 \%$ [2].

It is widely accepted that, above the discriminatory zone of $1,500 \mathrm{mIU} / \mathrm{mL}-2,500 \mathrm{mIU} / \mathrm{mL}$, a normal intrauterine pregnancy should be visible by TVS. The absence of which implies abnormal gestation [3].

Laparoscopy is the gold standard for diagnosing ectopic pregnancy and also it is possible to do conservative surgical procedures with less morbidity [4-6]. Available online at: www.medresearch.in 35 | P a g e 


\section{Original Research Article}

Methotrexate is the first successfully used drug in clinical practice for un-ruptured ectopic pregnancy which is a folic acid antagonist. In 1985 Chotiner was the first in English literature to describe a patient with tubal pregnancy treated successfully with systemic methotrexate [6]. So this study was aimed to analyse the morbidity and mortality in women with ectopic pregnancy.

\section{Materials and Methods}

Design of study: This prospective cross sectional study conducted between June 2014- June 2016.

Setting: Department of Obstetrics \& Gynaecology, Vinayaka Mission's Medical College, Karaikal, Puducherry, for a period of 2 years (June 2014 - June 2016).

Study Population: 70 cases of ectopic pregnancy were diagnosed and recruited for the study after taking their consent for participation.

Inclusion Criteria-All the cases diagnosed as ectopic pregnancy admitted to RIMS General hospital, KADAPA, during the study period of 2 years.

Exclusion Criteria: All intrauterine pregnancies Method of study

- Detailed history was taken.

- General, systemic, abdominal and vaginal examinations were done.

- Informed consent was taken and data were recorded on the Proforma.

- TVS / TAS was done to diagnose and to know the severity of the condition.
- Apart from routine surgical profile, $\beta-\mathrm{hCG}$ assay, UPT, coagulation profile, Renal function tests, Liver function tests were done.

Patients were treated by different treatment modalities based on their hemodynamic stability.

The diagnosis of ectopic pregnancy was confirmed by histo-pathological examination of the specimen after surgery. The morbidity and mortality associated with ectopic pregnancy was assessed.

Serum $\beta$-hCG assay: Modern assays for the $\beta$-subunit of hCG are highly sensitive and specific, with detection levels below $5 \mathrm{mIU} / \mathrm{mL}$.

\section{Ultrasound:}

- Transabdominal USG: In transabdominal USG, intrauterine gestational sac should appear when the serum hCG levels are 6000 - $6500 \mathrm{mIU} / \mathrm{mL}$. The absence of an apparent intrauterine sac with hCG levels at or above $6000 \mathrm{mIU} / \mathrm{mL}$ suggests an abnormal pregnancy, either ectopic or spontaneous abortion.

- Transvaginal USG: Transvaginal USG is superior to transabdominal USG in diagnosing ectopic pregnancy. A 3 - $5 \mathrm{MHz}$ transvaginal transducer allows for a deeper penetration of the pelvis than transducers of higher frequency, whereas a 7.5 MHz transvaginal transducer provides better near-resolution at the cost of shallower penetration.

Statistical Analysis: Data was collected and tabulated as shown in results. Statistical analysis was done using Microsoft Excel. Frequency and percentage of each parameter was calculated and analysed.

\section{Results}

In the present study 70 patients with ectopic pregnancy were recruited, management and outcome were analysed. Out of 70 patients, 62(88.5\%) patients were managed by laparotomy, 7 (10\%) patients were by laparoscopically, one patient (1.4\%) was successfully managed by medical therapy. In the present study group, one patient with unruptured ectopic was planned for medical therapy. She was treated with single dose therapy.

Operative Findings-In our study group, 30 patients had less than $1000 \mathrm{ml}$ of hemoperitoneum, 30 patients had hemoperitoeum of $1000-2000 \mathrm{ml}$ and 2 patients had $>2000 \mathrm{ml}$ of hemoperitoneum intra-operatively.

Regarding side of ectopic ,62 patients were underwent surgical treatment of this, $51.02 \%$ patients had ectopic pregnancy on right side and $46.8 \%$ had ectopic pregnancy on left side.

In the present study group, 62 patients were successfully managed by surgical management . 1 patient with tubal pregnancy were successfully treated by medical therapy.

The most common site for ectopic was found in ampulla in 52(74\%) patients, followed by isthmus $6(8.24 \%)$, ovary 5 (7.14\%), interstitial $1(1.4 \%)$, cornua $2(2.28 \%)$, fimbria $2(2.28 \%)$ and infundibulam $2(2.28 \%)$ (table 1$)$. 
Table-1: Ectopic pregnancy - Site of ectopic

\begin{tabular}{|l|l|l|}
\hline Site of ectopic & Number (total cases =70) & Percentage (\%) \\
\hline Ampulla & 52 & $74.2 \%$ \\
\hline Isthmus & 6 & $8.2 \%$ \\
\hline Cornua & 2 & $2.8 \%$ \\
\hline Interstitial & 1 & $1.4 \%$ \\
\hline Ovary & 5 & $7.14 \%$ \\
\hline Fimbria & 2 & $2.8 \%$ \\
\hline Infundibulam & 2 & $2.8 \%$ \\
\hline
\end{tabular}

Table-2: Ectopic pregnancy-Procedure done

\begin{tabular}{|l|l|l|}
\hline Procedure & Number (n) & Percentage (\%) \\
\hline Salpingectomy & 48 & $77.91 \%$ \\
\hline Salpingo-oopherectomy & 10 & $16.12 \%$ \\
\hline Oopherectomy & 3 & $4.83 \%$ \\
\hline Fimbriectomy & 1 & $1.61 \%$ \\
\hline
\end{tabular}

Out of 62 patients, 55 patients $(88.83 \%)$ presented with ruptured ectopic pregnancy, $2(3.2 \%)$ had unruptured ectopic and 2patients $(3.2 \%)$ had tubal abortion at the time of surgery. In this study group, 48 patients were managed by salpingectomy $(77.41 \%)$, followed by salpingo-oophorectomy in $10(16.12 \%)$ patients. Oopherectomy was done in $3(4.83 \%)$ and fimbriectomy was done in one (1.61\%) patient (Table 2). Out of 70 patients, 7 patients were treated laparoscopically . In our study, out of 70 patients, $68(98 \%)$ patients required blood transfusions.

Morbidity- In our study group about morbidity, 67 cases post operative period was uneventful, 3 (4.2\%) cases were admitted in ICU

\section{Discussion}

One out of every 100 to 300 pregnancies is ectopic, and the prevalence is increasing. The classic triad of symptoms, amenorrhea, abdominal pain, and abnormal bleeding, varies greatly among individuals, and ectopic pregnancies frequently are confused with other conditions, such as ovarian cyst, pelvic inflammatory disease, and spontaneous abortion. Ruptured ectopic pregnancies cause hemorrhage and shock and are the leading cause of maternai mortality in the first trimester. Although conservation surgery and tuboplasty have improved the fertility outlook of the ectopic patient, only one-third of such women will be delivered of a live baby.

Ectopic pregnancies with sac measuring less than $3.5 \mathrm{cms}$, absence of fetal cardiac activity, and those with hCG levels lesser than 3,000 $\mathrm{mIU} / \mathrm{mL}$ were taken as inclusion criteria for medical therapy [7].

In the present study group, medical therapy was given in one patient. She was managed successfully by single dose MTX. Her $\beta$-hCG level came to pre-pregnancy level $(<5 \mathrm{mIU} / \mathrm{mL})$ and USG showed complete resolution of ectopic by 2 nd -4 th week during follow up.

In the present study, hemoperitoneum was present in $97.95 \%$ of the cases which is close to the study done by

Obsgyne Review: Journal of Obstetrics and Gynecology
Shrestha et al., [8] (87.5\%). Massive hemoperitoneum of about 2000-2500 $\mathrm{ml}$ was present in 4 cases.

On laparotomy ectopic pregnancy was present on right side in $51.02 \%$ of the patients which correlates with the studies done by Kopani et al[9] (56.2\%) and Etuknwa Bassey Tom et al., [10] (51.4\%). The right sided preponderance was due to sub-clinical appendicitis.

In the present study group, 4(8\%) patients underwent laparoscopy which is minimally invasive and is the gold standard for diagnosing ectopic pregnancy.

This Ectopic pregnancy in ampulla was present in $74.42 \%$ of the cases which correlates with the study done by Poonam et al, [11] (62.6\%). Most of the studies show ampulla as the common site for ectopic pregnancy. This may be because fertilization occurs in the ampullary region. Ampulla has numerous plica and these plica agglutinate due to PID leading to entrapment of zygote. Isthmic pregnancy was seen in $12.24 \%$ of the cases, interstitial pregnancy in $2.02 \%$. Ovarian pregnancy was diagnosed in $10.20 \%$ of the cases.

In the present study, $93.83 \%$ of the cases had ruptured ectopic and is correlating with the study done by Yakasai

Available online at: www.medresearch.in 37 | P a g e 
Original Research Article

et al [12] (86.14\%). 5.08\% of the patients had un-ruptured ectopic. Tubal abortion was noted in $4.08 \%$ cases.

In the present study, depending on hemodynamic stability and patients wish to retain fertility, various procedures were done by laparotomy and laparoscopically. Salpingectomy was done in $77.94 \%$ of the patients which is close to the study done by Poonam et al., [11] (69.3\%) as most of the cases were with ruptured ectopic.

Salpingo-oophorectomy and fimbriectomy were done in $16.24 \%$ and $4.83 \%$ respectively, which correlates with the study done by Rashmi A Gaddagi et al., [13].

In our study group, post-operative period was uneven full in $95.91 \%$ of cases. $4.08 \%$ were admitted to MICU due to complications of acute blood loss, acute renal failure and recovered well. $98 \%$ of the patients received blood transfusions for correcting blood loss. No case of mortality was registered during the study period.

\section{Conclusion}

Ectopic pregnancy is the commonest cause of pregnancy related deaths in the first trimester. Worldwide there is an increased incidence over the past three decades accounting for $1.8-2 \%$ of all pregnancies. High index of suspicion is necessary for early diagnosis before its rupture as it gives an opportunity for conservative treatment. Early diagnosis and prompt conservative surgical or medical management not only reduces maternal morbidity and mortality but also helps in preserving fertility.

Funding: Nil, Conflict of interest: Nil

Permission from IRB: Yes

\section{References}

1. Gary Cunningham F, Kenneth J. Leveno, Steven L. Bloom, John C. Hauth, Dwight J. Rouse, Catherine Y. Spong. Williams Obstetrics. $23^{\text {rd }}$ edition, 2010 by The Mc Grew-Hill Companies; Chapter 10, Ectopic pregnancy; 238-254.

2. Barnhart K, Mennuti MT, Benjamin I, Jacobson S, Goodman D, Coutifaris C. Prompt diagnosis of ectopic pregnancy in an emergency department setting. Obstet Gynecol. 1994 Dec;84(6):1010-5.

3. Barnhart K, Esposito M, Coutifaris C. An update on the medical treatment of ectopic pregnancy. Obstet Gynecol Clin North Am. 2000 Sep;27(3):653-67, viii.

4. Kadar N. Early recourse to laparoscopy in the management of suspected ectopic pregnancy. Accuracy and morbidity. J Reprod Med. 1990 Dec;35(12):1153-6.

5. Samuelsson S, Sjövall A. Laparoscopy in suspected ectopic pregnancy. Acta Obstet Gynecol Scand. 1972; 51(1):31-5.

6. Chotiner HC. Nonsurgical management of ectopic pregnancy associated with severe hyperstimulation syndrome. Obstet Gynecol 1985; 66:740-3.

7. Khaleeque F, Siddiqui RI, Jafarey SN. Ectopic pregnancies: a three year study. J Pak Med Assoc. 2001 Jul; 51(7):240-3.

8. Shrestha J, Saha R. Comparison of laparoscopy and laparotomy in the surgical management of ectopic pregnancy. J Coll Physicians Surg Pak. 2012 Dec;22 (12): 760-4. doi: 12.2012/JCPSP.760764.

9. Kopani F, Rrugia A, Manoku N. Ectopic pregnancy comparison of different treatments. J Prenat Med. 2010 Apr;4(2):30-4.

10. Etuknwa Bassey Tom, Azu Onyemaechi Okpara, Peter Aniekan Imo, Ekandem Gabriel John et al. Ectopic pregnancy: A Nigerian Urban Experience. Korean J Obstet Gynecol 2012;55(5):309-314.

11. Poonam, Uprety D, Banerjee B. Ectopic pregnancy two years review from BPKIHS, Nepal. Kathmandu Univ Med J (KUMJ). 2005 Oct-Dec;3(4):365-9.

12. Yakasai IA, Abdullahi J, Abubakar I. Management of ectopic pregnancy in Aminu Kano Teaching Hospital Kano Nigeria: A 3- year. Global Adv Res J Med Med Sci 2012;1(7):181-5.

13. Rashmi AGaddagi, AP Chandrashekhar.A . Clinical Study of Ectopic Pregnancy.JCDR 2012;6:867-869.

\section{How to cite this article?}

Anis F, Malarvizhi G, Narmadha NS, Reddy AS. A prospective study of morbidity patterns in ectopic pregnancy at a tertiary care hospital. Obs Rev:J obstet Gynecol 2016;2(3):35-38. doi: 10.17511/joog.2016.i03.03. 